\title{
Identification of individual DNA molecule of Mycobacterium tuberculosis by nested PCR-RFLP and capillary electrophoresis
}

\author{
Po-Ling Chang ${ }^{\mathrm{a}}$, Wen-Shyang Hsieh ${ }^{\mathrm{b}}$, Chia-Lien Chiang ${ }^{\mathrm{b}}$, Belinda Yen-Liberman ${ }^{\mathrm{c}}$, \\ Gary W. Procop ${ }^{\mathrm{c}}$, Huan-Tsung Chang ${ }^{\mathrm{a}, *}$, Hsin-Tsung Ho ${ }^{\mathrm{b}, \mathrm{d}, * *}$ \\ a Department of Chemistry, National Taiwan University, Taipei, Taiwan, ROC \\ b Department of Laboratory Medicine, Mackay Memorial Hospital, Taipei, Taiwan, ROC \\ ' Section of Clinical Microbiology, Department of Clinical Pathology, The Cleveland Clinic, Cleveland, OH, USA \\ ${ }^{\mathrm{d}}$ Mackay Medicine, Nursing and Management College, Taipei, Taiwan, ROC
}

\section{A R T I C L E I N F O}

\section{Article history:}

Received 2 March 2008

Received in revised form 4 June 2008

Accepted 5 June 2008

Available online 12 June 2008

\section{Keywords:}

Capillary electrophoresis

Heat shock protein 65

Mycobacterium tuberculosis

Poisson distribution

Single-molecule detection

\begin{abstract}
A B S T R A C T
The improvement of sensitivity and differentiation in rapidly identifying a small amount of mycobacteria in sputum has significant implications for reducing tuberculosis transmission. We previously applied the conventional PCR and capillary electrophoresis (CE) to establish the restriction fragment length polymorphism (RFLP) pattern of mycobacterial 65-kDa heat shock protein (hsp65) gene from colony specimens. However, the previous analysis did not provide enough sensitivity for sputum specimens in which the limitation of analysis might be hindered by PCR inhibitors and primer-dimers formation during amplification. In the current study, nested PCR (nPCR) had been redesigned for PCR-RFLP analysis (PRA) of mycobacterial hsp65 gene using CE. The results show both Mycobacterium tuberculosis complex and mycobacteria other than tuberculosis could be identified in the presence of PCR inhibitors. The interference due to primerdimers was also minimized. Based on the Poisson distribution, the repeatability of single DNA molecule detection was greatly affected by sampling probability and might be improved significantly by increasing the sample loading. The PRA using NPCR and CE is not only able to detect the individual mycobacterial DNA molecule but also potentially differentiate the species.
\end{abstract}

(c) 2008 Elsevier B.V. All rights reserved.

\section{Introduction}

Reduction of Mycobacterium tuberculosis (MTB) transmission is an important issue. One-third of the global population is believed to be infected with bacteria of the M. tuberculosis complex, the causative agent of tuberculosis. More than 8 million new cases of tuberculosis occur annually leading to 2 million deaths [1]. In addition, the mycobacteria other than tuberculosis (MOTT) also cause human diseases and are crucial to be correctly identified because of differences in antimicrobial susceptibility [2]. For rapid identification of MTB and MOTT, a wide-range of nucleic acid amplification tests has been developed. Several of them based upon species-specific probes are commercially available, including PCR-based Amplicor (Roche), transcription-mediated amplification (Gen-Probe), strand displacement amplification (Becton Dickin-

\footnotetext{
* Corresponding author. Tel.: +886 233661171; fax: +886 233661171.

** Corresponding author at: Mackay Medicine, Nursing and Management College, Taipei, Taiwan, ROC. Tel.: +886 910014300; fax: +886 225433638 .

E-mail addresses: changht@ntu.edu.tw (H.-T. Chang), drho@ms2.mmh.org.tw (H.-T. Ho).
}

son), and ligase-chain reaction (Abbott) [3-6]. So far, limited numbers of identifiable species and high-cost of probe-based methods have restricted their routine use for clinical specimens. On the other hand, many endonuclease-based methods without costly probes have also been proposed for differentiating mycobacterial species [7-9]. These non-probe methods utilize enzymatic digestion of amplified genetic products and electrophoretic separation to obtain the restriction fragment length polymorphism (RFLP) pattern. Such a diagnostic algorithm, known as PCR-RFLP analysis (PRA), remains cumbersome and requires two or more restriction endonucleases to achieve a higher discriminatory power. Up to now, the sensitivity and specificity of both probe and nonprobe methods are still insufficient to detect and differentiate a low copy number of DNA or a small amount of mycobacteria $[10,11]$.

Capillary electrophoresis (CE) with laser-induced fluorescence has become a powerful analytical tool for bio-analysis mainly due to its high sensitivity, excellent efficiency, rapidity, less sample requirement, and thus, toward to system biology [12,13]. In the previous studies, our team demonstrated the performance of $\mathrm{CE}$ that could be applied to clinical microbiological diagnosis $[14,15]$. However, the PRA using conventional PCR and CE did not pro- 
vide enough sensitivity for specimens directly from clinical isolates such as sputum. The limitation of analysis of sputum might be resulted from the presence of PCR inhibitors and primer-dimer formation during amplification. In the current study, nPCR had been re-designed for the PRA using CE in the presence of electroosmotic flow $[16,17]$ to improve the sensitivity and specificity. The sampling impacts of identifying individual mycobacterial DNA were carefully estimated by rational explanation. The performance of this analysis, including the limit of detection, specificity of RFLP, and interferences by PCR inhibitors and primer-dimers, were evaluated for a limited number of specimens from colonies and sputum.

\section{Materials and methods}

\subsection{Specimens and DNA preparation}

We studied three mycobacterial strains, M. tuberculosis (ATCC 10709) from the American Type Culture Collection (Rockville, MD), Mycobacterium heckashorne (CCF 21) and Mycobacterium celatum (CCF 56); the latter two were from the culture collection of clinical microbiology section of Cleveland Clinic, Cleveland, OH, USA, and had been previously characterized using DNA sequencing. A loop from each cultured strain was suspended in $500 \mu \mathrm{L}$ of TE buffer (10 mM Tris-HCl, $1 \mathrm{mM}$ EDTA, pH 8.0) and inactivated by boiling for $10 \mathrm{~min}$. The boiled specimen of $M$. tuberculosis was subjected to DNA extraction by Qiagen mini DNA purification kit (Gentra Systems, MN, USA) according to the manufacturer's instructions. The DNA concentration was determined using a Beckman DU460 UV-vis spectrophotometer (Fullerton, CA, USA). For testing the interference of inhibitors, we did not treat the boiled specimens of $M$. heckashorne and M. celatum with DNA extraction. Nine specimens of sputum positive for acid-fast bacilli (AFB) collected at the department of laboratory medicine, Mackay Memorial Hospital, Taipei, Taiwan were also analyzed. All sputum specimens were digested with $\mathrm{N}$-acetyl-L-cysteine and decontaminated with $4 \% \mathrm{NaOH}$. Each specimen was then concentrated by centrifugation $(3000 \times g)$ before examination by Kinyoun stain and microscopy. The interpretation of AFB smear was scored as follows [18]. The scores $4+, 3+, 2+$, and $1+$, indicated $>9$ AFB per field $(1000 \times)$, 1-9 AFB per field, 1-9 AFB per 10 fields, and 1-9 AFB per 100 fields, respectively. Aliquots of sputum specimens were inoculated in both liquid (BACTEC MGIT 960, Becton Dickinson Bioscience, Sparks, MD) and solid (Löwenstein-Jensen) culture medium for the isolation and identification of mycobacteria. Identification at the species level was done by classical biochemical tests and further confirmed by DNA sequence analysis. Meanwhile, duplicate aliquots of sputum specimens were subjected to DNA extraction followed by PRA with CE (PRACE). The analytical laboratory performing CE was blinded with respect to the results of AFB smear and culture.

\subsection{PCR amplification and enzymatic digestion}

All specimens were investigated by using traditional PCR and $\mathrm{nPCR}$ for comparison. PCR mixtures contained $2.5 \mu \mathrm{L}$ of $10 \times$ buffer concentrate, $0.4 \mu \mathrm{M}$ (each) primer, $200 \mu \mathrm{M}$ concentrations of each of four dNTPs, 1.0 unit of FastStart Taq DNA polymerase (Roche, Indianapolis, IN), and 1 or $10 \mu \mathrm{L}$ of the DNA template (extracted from colonies or sputum) in a final volume of $25 \mu \mathrm{L}$. Amplification primers previously reported by Telenti et al. (Tb11 and Tb12) were chosen for traditional PCR [19]. The primers and other optimizations were redesigned for the nPCR protocol (Table 1). The external primers (Tb-ExF and Tb-ExR) were modified from the primers (M1 and M4) as reported by Bascunana and Belak [20]. Thermocycling of reaction mixtures was performed in a model 2700 Thermocycler (PerkinElmer-Applied Biosystems, USA) programmed for 40 cycles $\left(30 \mathrm{~s}\right.$ at $95^{\circ} \mathrm{C}, 30 \mathrm{~s}$ at $60-68^{\circ} \mathrm{C}, 60 \mathrm{~s}$ at $72{ }^{\circ} \mathrm{C}$ ) and followed by a 7 -min incubation at $72{ }^{\circ} \mathrm{C}$ (Table 1 ). Within the mycobacterial genome, a target of $461 \mathrm{bp}$ fragment was amplified with external primers in first PCR of nPCR. Then, $1 \mu \mathrm{L}$ out of $25 \mu \mathrm{L}$ PCR products was transferred into a new reaction tube for second PCR of nPCR using internal primers. The internal primers ( $\mathrm{Tb}-\mathrm{InF}$ and $\mathrm{Tb}-\mathrm{InR}$ ) were elongated to $27 \mathrm{bp}$ and annealed to the same locations from $5^{\prime}$ position of heat shock protein 65 (hsp65) gene as those by Telenti primers (Tb11 and Tb12). The size of nPCR products of hsp65 gene that confirmed by sequencing were $441 \mathrm{bp}$ (MTB and $M$. celatum) or $442 \mathrm{bp}$ ( $M$. heckashorne and Mycobacterium abscessus), respectively. Amplification products were then digested with restriction endonuclease HaeIII (Roche, Indianapolis, IN, USA). Thus $5 \mu \mathrm{L}$ of the amplified reaction solution was added to a mixture containing $0.2 \mu \mathrm{L}$ of enzyme ( 2 units), $2.5 \mu \mathrm{L}$ of restriction buffer $(10 \times)$, and $17.3 \mu \mathrm{L}$ of sterile distilled water. The mixtures were incubated for $60 \mathrm{~min}$ at $37^{\circ} \mathrm{C}$ for HaeIII digestion. We used a reference strain of MTB as positive control and healthy human genomic DNA as negative control. In no case were contaminations due to the transfer of PCR products into a new reaction tube observed. To examine the capability of single-molecule detection, we prepared mycobacterial DNA templates to the equivalent content of one bacillus by serial dilution with ribonuclease-free water (Invitrogen, Carlsbad, CA, USA).

\subsection{Separation of $P C R$ products by agarose gel electrophoresis and capillary electrophoresis}

Undigested amplified reaction mixtures, $10 \mu \mathrm{L}$ from conventional PCR or $2 \mu \mathrm{L}$ from nPCR, were loaded in each well for $3 \%$ agarose gel electrophoresis. The gel was prepared in $0.5 \times$ TAE buffer containing $0.5 \mu \mathrm{g} / \mathrm{mL}$ ethidium bromide and the separation was run at $8 \mathrm{~V} / \mathrm{cm}$ under ambient temperature. After electrophoretic separation, the band pattern was observed and demonstrated by ImageMastes recorder of Amersham Pharmacia Biotech (Piscat-

Table 1

Primers and thermocycles designed for conventional and nested PCR

\begin{tabular}{|c|c|c|c|c|c|c|}
\hline \multirow{2}{*}{\multicolumn{2}{|c|}{$\begin{array}{l}\text { Primers } \\
\text { Telenti primers of conventional PCR }\end{array}$}} & \multicolumn{5}{|c|}{ Thermocycles } \\
\hline & & 40 сус & & & & \\
\hline Tb11 & 5'-ACCAACGATGGTGTGTCCAT-3' & $95^{\circ} \mathrm{C}$ & $95^{\circ} \mathrm{C}$ & $60^{\circ} \mathrm{C}$ & $72{ }^{\circ} \mathrm{C}$ & $72^{\circ} \mathrm{C}$ \\
\hline Tb12 & 5'-CTTGTCGAACCGCATACCCT-3' & $6 \mathrm{~min}$ & $30 \mathrm{~s}$ & $30 s$ & $60 s$ & $7 \mathrm{~min}$ \\
\hline \multicolumn{2}{|c|}{ External primers of nested PCR } & \multicolumn{5}{|c|}{40 cycles } \\
\hline Tb-ExF & 5'-CCCCACGATCACCAACGATG-3' & $95^{\circ} \mathrm{C}$ & $95^{\circ} \mathrm{C}$ & $61^{\circ} \mathrm{C}$ & $72{ }^{\circ} \mathrm{C}$ & $72{ }^{\circ} \mathrm{C}$ \\
\hline Tb-ExR & 5'-CCGAGATGTAGCCCTTGTCGA-3' & $6 \mathrm{~min}$ & $30 s$ & $30 s$ & $60 s$ & $7 \mathrm{~min}$ \\
\hline \multicolumn{2}{|c|}{ Internal primers of nested PCR } & \multicolumn{5}{|c|}{40 cycles } \\
\hline Tb-InF & 5'-ACCAACGATGGTGTGTCCATCGCCAAG-3' & $95^{\circ} \mathrm{C}$ & $95^{\circ} \mathrm{C}$ & $68^{\circ} \mathrm{C}$ & $72^{\circ} \mathrm{C}$ & $72{ }^{\circ} \mathrm{C}$ \\
\hline Tb-InR & 5'-CTTGTCGAACCGCATACCCTCGGTGAG-3' & $6 \mathrm{~min}$ & $30 \mathrm{~s}$ & $30 \mathrm{~s}$ & $60 s$ & $7 \mathrm{~min}$ \\
\hline
\end{tabular}


away, NJ). We considered the band located within 400-500 bp range as $h s p 65$ gene product.

Amplicons and digested restriction fragments were analyzed by $C E$ with laser-induced fluorescence using poly(ethylene oxide) (PEO) solution in the presence of electroosmotic flow. PEO with the molecular weight of $8,000,000 \mathrm{~g} / \mathrm{mol}$ was purchased from Sigma-Aldrich (St Louis, MO, USA). Briefly, a high-voltage power supply (Gamma High Voltage Research Inc., Ormond Beach, FL) was used to drive electrophoresis. The entire detection system was enclosed in a black box with a high-voltage interlock. The highvoltage end of the separation system was put in a laboratory-made plexiglass box for safety. A 5.0-mW solid laser with $532 \mathrm{~nm}$ output from Uniphase (Mantence, CA, USA) was used for excitation. The light was collected with a $10 \times$ objective (numerical aperture $=0.25$ ). One RG 610 cut-off filter was used to block scattered light before the emitted light reached the phototube (Hamamatsu R928). The amplified currents were transferred directly through a $10-\mathrm{k} \Omega$ resistor to a 24-bit A/D interface at $10 \mathrm{~Hz}$ (Borwin, JMBS Developments, Le Fontanil, France) and stored in a personal computer. Bare fused-silica capillaries (Polymicro Technologies, Phoenix, AZ, USA) with an internal diameter of $75 \mu \mathrm{m}$ were used for DNA separations without any further coating process. The capillary length was $40 \mathrm{~cm}$ and the length from the injection end to the detector was $30 \mathrm{~cm}$. Anodic and cathodic vials were filled with $1.5 \%$ PEO solution that was prepared in $100 \mathrm{mM}$ Tris-boric acid buffer ( $\mathrm{pH}$ 9.0) containing $25 \mu \mathrm{g} / \mathrm{mL}$ ethidium bromide (Pharmacia Biotech, Sweden). A capillary was filled with $1.5 \mathrm{M}$ Tris-boric acid buffer ( $\mathrm{pH}$ 10.0) and then the DNA specimen was introduced from the inlet (anodic) end of the capillary by hydrodynamic injection at $30-\mathrm{cm}$ height (the difference between the specimen vial and the cathodic vial) for $10 \mathrm{~s}$. During the separation at $20 \mathrm{kV}$, neutral PEO molecules entered the capillary from the anodic end via electroosmotic flow. The DNA fragments migrating against electroosmotic flow entered PEO solution and were separated
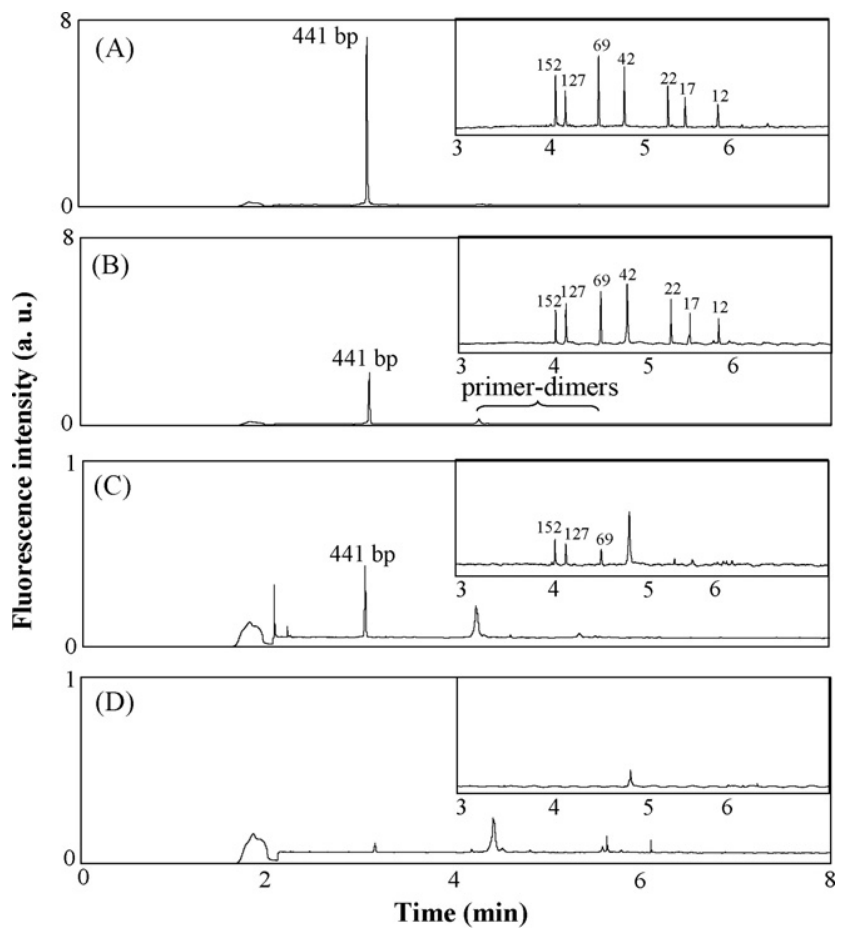

Fig. 1. CE of conventional PCR products using Telenti primers and MTB DNA templates in the amounts of $0.5 \mathrm{ng}(\mathrm{A}), 50 \mathrm{pg}(\mathrm{B}), 5 \mathrm{pg}(\mathrm{C})$, and $0.5 \mathrm{pg}(\mathrm{D})$. The inserts are corresponding RFLP patterns of 441-bp hsp65 gene after enzymatic digestion. according to the sieving mechanism at ambient temperature and pressure.

\section{Results and discussion}

\subsection{Comparison of the primer-dimer interference between conventional PCR and nested PCR}

In order to assess the reduction of primer-dimers and the superior sensitivity of RFLP by the implementation of in PRACE, we simultaneously performed conventional PCR (Fig. 1) and nPCR (Fig. 2) amplifying mycobacterial hsp65 genes for comparison. As the capillary electrophoregrams demonstrate, conventional PCR using Telenti primers require at least $5 \mathrm{pg}$ of MTB DNA template to generate a 441-bp hsp65 gene peak (Fig. 1C). Furthermore, it requires no less than $50 \mathrm{pg}$ of MTB DNA template to obtain a full-range RFLP pattern (Fig. 1B). The formation of primer-dimers becomes obvious while MTB DNA templates less than $50 \mathrm{pg}$ are applied (Fig. 1C and D). In contrast, nPCR is able to yield taller hsp65 gene peaks and distinguishable species-specific RFLP patterns even with $5 \mathrm{fg}$ of MTB DNA template (Fig. 2E). With enough PCR cycles [21], the heights of nPCR hsp65 gene peaks remain almost identical regardless of declining MTB DNA template amounts (Fig. 2B-E). The primer-dimers seen in the first PCR using external primers (Fig. 2A) are no longer observed in the second PCR using internal primers (Fig. 2B-E). The disappearance of primer-dimers is partially due to a 25-fold dilution of the first PCR products which contribute a much higher product/primer ratio for the second PCR amplification. The

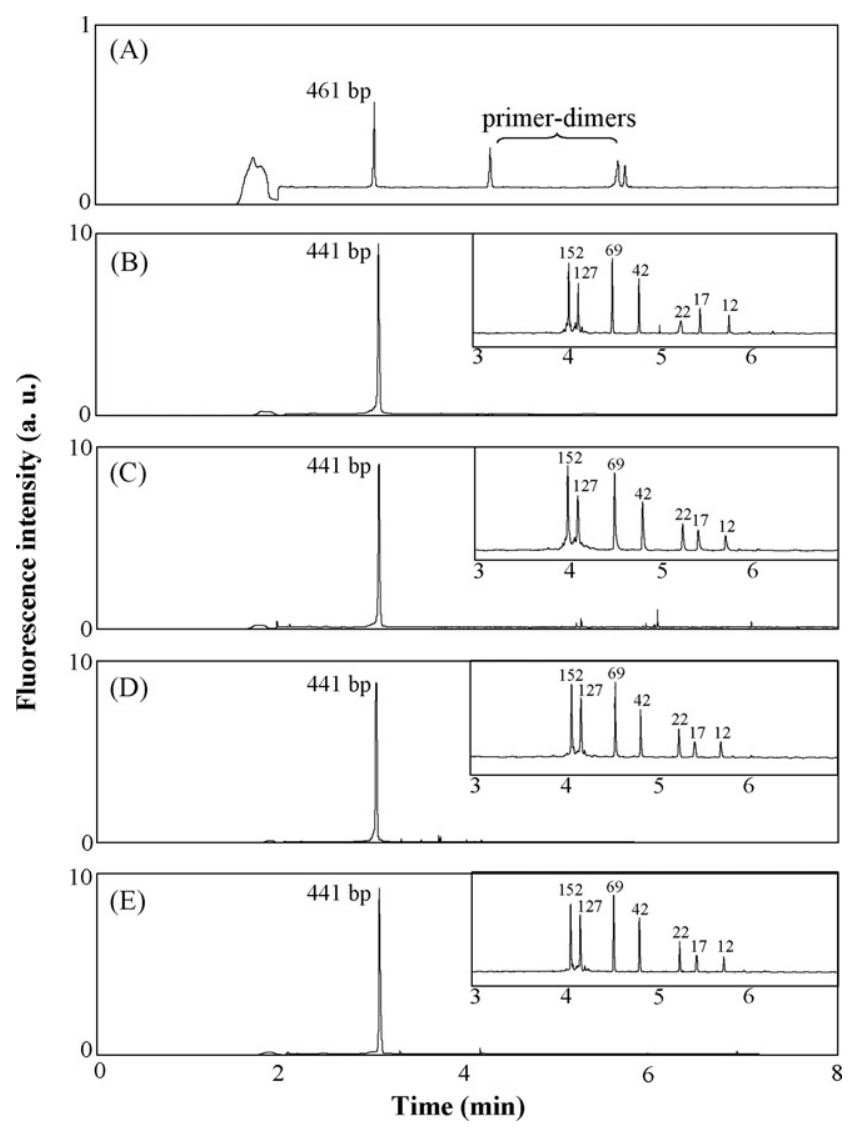

Fig. 2. CE of final nPCR products using MTB DNA templates in the amounts of $5 \mathrm{pg}$ (B), $0.5 \mathrm{pg}(\mathrm{C}), 50 \mathrm{fg}(\mathrm{D})$, and $5 \mathrm{fg}$ (E). The first PCR with external primers yields 461bp gene products (A). The second PCR with internal primers generate 441-bp hsp65 gene products (B-E). The inserts are corresponding RFLP patterns of $h s p 65$ gene after enzymatic digestion. 

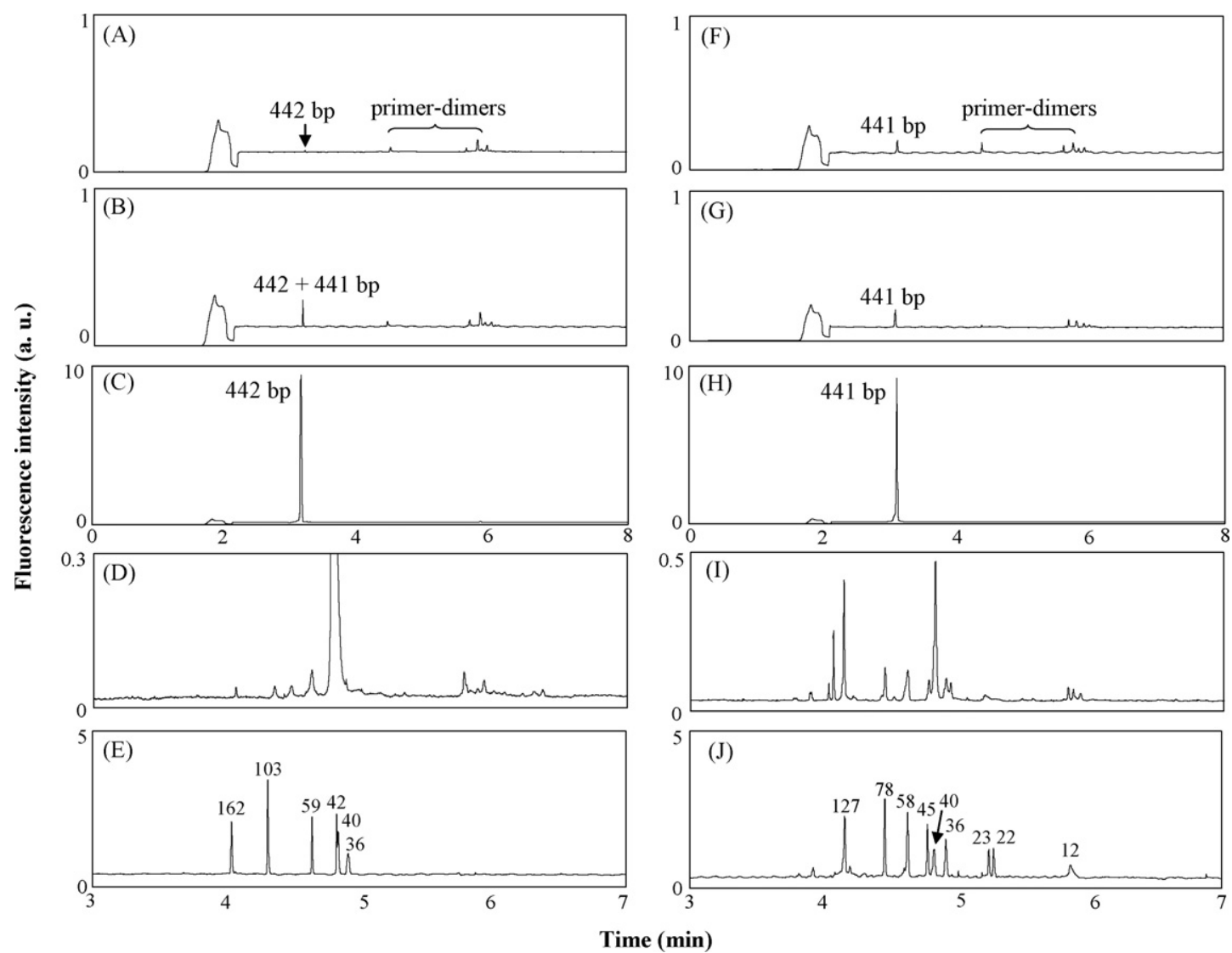

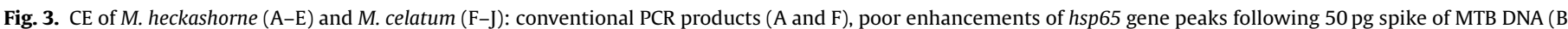
and $\mathrm{G}$ ), the nPCR products ( $\mathrm{C}$ and $\mathrm{H}$ ), RFLP patterns of conventional PCR products (D and I), RFLP patterns of nPCR products (E and J).

$7^{\circ} \mathrm{C}$ increase of the second PCR annealing temperature also diminishes interactions between external and internal primers. Thus, as compared with conventional PCR, the implementation of nPCR not only avoids the interference of primer-dimers but also makes PRA 10,000 times more sensitive without losing specificity of RFLP pattern.

\subsection{Comparison of the PCR inhibitor interference between conventional PCR and nested PCR}

Unlike the existence of numerous bacilli in the cultured specimens, direct clinical isolates such as sputum frequently contain merely a few mycobacteria and sometimes inhibitors that interfere with the performance of PCR. Various attempts have been made to reduce PCR inhibition in diagnostic tests [22]. For respiratory and non-respiratory specimens studied by Böddinghaus et al. [23], the overall inhibition rate of PCR using Amplicor kit was $12.5 \%$ which could be reduced to $1.1 \%$ with the addition of silica membrane DNA purification. During previous RFLP study of multiple cultured mycobacteria, we found two specimens of $M$. heckashorne and $M$. celatum exhibiting potent inhibition of conventional PCR when the specimens were not treated with DNA extraction. Fascinatingly, the replacement of conventional PCR with nPCR can overcome the interference of inhibitors. As shown by capillary electrophoregrams, conventional PCR products of $M$. heckashorne and M. celatum contain tiny or small peak of hsp65 gene (Fig. 3A and F). Coexistence of remarkable primer-dimers is also noted. The presence of inhibitors in both specimens is indicated by the poor enhancement of $h s p 65$ gene peak following $50 \mathrm{pg}$ spike of MTB DNA (Fig. 3B and G). When analyzed by
nPCR in contrast to conventional PCR, the formation of primerdimers and the inhibition of amplification disappear as evidenced by a solitary and sharp hsp65 gene peak of 10 -fold more height (Fig. 3C and $\mathrm{H}$ ). After the enzymatic digestion, RFLP patterns of conventional PCR products are unrecognizable (Fig. 3D and I). On the contrary, RFLP patterns resulting from nPCR products are unambiguous and species-specific (Fig. 3E and J). The above examples of cultured MOTT demonstrate that mycobacteria could be identified without DNA extraction or even in the presence of inhibitors.

\subsection{Sampling effect in identifying individual mycobacterial DNA molecule}

Nested PCR is a more efficient approach towards identifying a low copy number of DNA and has been applied for the molecular diagnosis of tuberculosis [3-6]. Recently, Lu et al. modified this approach and proved its ability for the analysis of single DNA molecule, so called single-molecule PCR [24]. During singlemolecule PCR, the single DNA molecule as a template is picked up by atomic force microscopy tips [24] or prepared by serial dilution $[25,26]$. To examine the capability of single-molecule detection, we conduct nPCR of hsp65 gene using MTB DNA templates of following concentrations and volumes: $50 \mathrm{fg} / \mu \mathrm{L} \times 1 \mu \mathrm{L}, 5 \mathrm{fg} / \mu \mathrm{L} \times 1 \mu \mathrm{L}$, and $0.5 \mathrm{fg} / \mu \mathrm{L} \times 10 \mu \mathrm{L}$. For each preparation, 16 aliquots are subjected to nPCR for three times. The probability of nPCR gene production is evaluated by the presence of $h s p 65$ gene bands on $3 \%$ agarose electrophoretic gels. For $50 \mathrm{fg} / \mu \mathrm{L} \times 1 \mu \mathrm{L}$ aliquots (Fig. 4A), the probability reaches $100 \%(16 / 16,16 / 16,16 / 16)$. For $5 \mathrm{fg} / \mu \mathrm{L} \times 1 \mu \mathrm{L}$ aliquots (Fig. $4 \mathrm{~B}$ ), the probability ranges from 25 to 

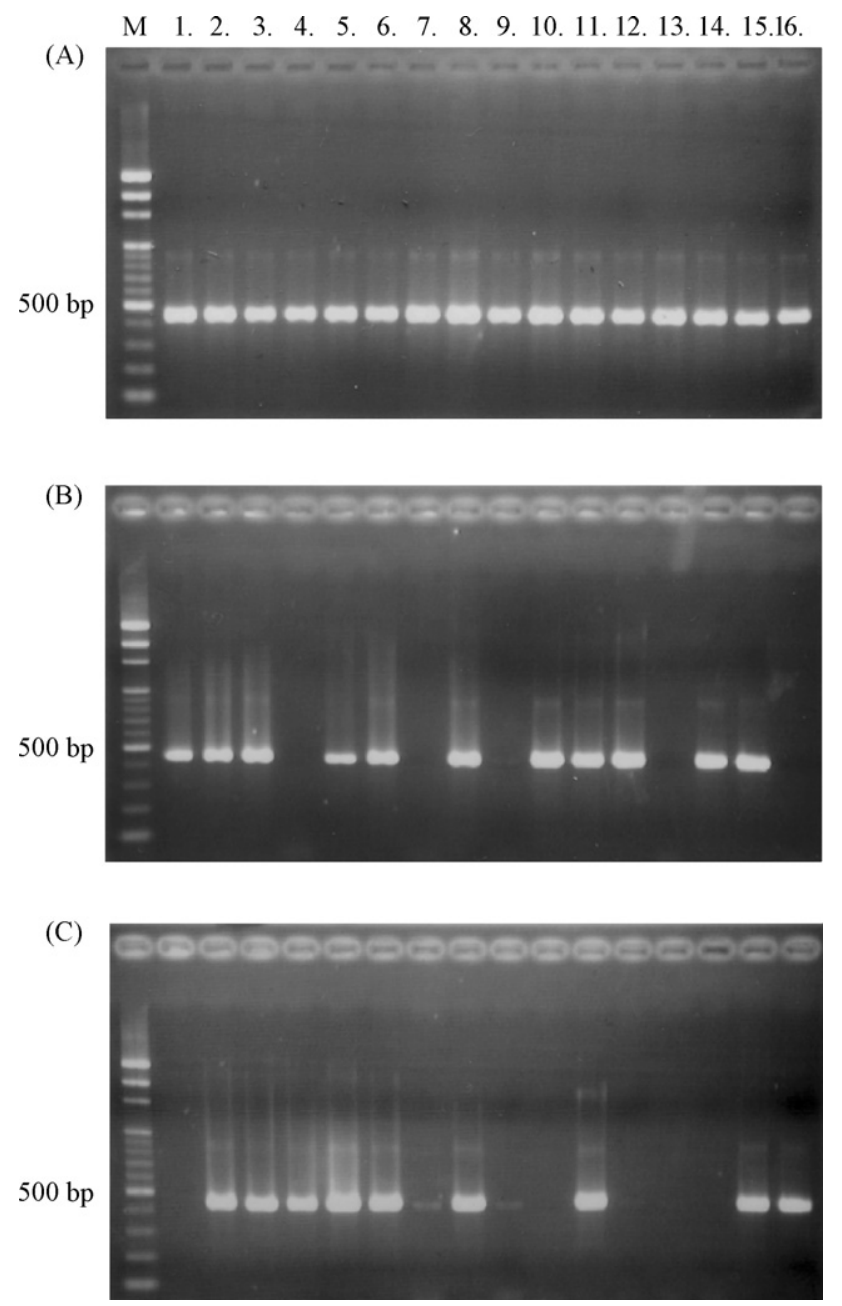

Fig. 4. Probabilities of $n P C R$ gene production using MTB DNA templates prepared in $50 \mathrm{fg} / \mu \mathrm{L} \times 1 \mu \mathrm{L}(\mathrm{A}), 5 \mathrm{fg} / \mu \mathrm{L} \times 1 \mu \mathrm{L}$ (B), and $0.5 \mathrm{fg} / \mu \mathrm{L} \times 10 \mu \mathrm{L}$ (C). Single-molecule DNA templates (B and $C$ ) are prepared by serial dilution. The final nPCR products are shown by the presence of $h s p 65$ gene bands on $3 \%$ agarose electrophoretic gels.

$68.8 \%(4 / 16,8 / 16,11 / 16)$. For $0.5 \mathrm{fg} / \mu \mathrm{L} \times 10 \mu \mathrm{L}$ aliquots (Fig. $4 \mathrm{C}$ ), the probability varies from 18.8 to $56.2 \%(3 / 16,6 / 16,9 / 16)$. Since the molecular weight of MTB DNA is $2.65 \times 10^{9} \mathrm{Da}$ [27], the DNA molecule in one bacillus averages $4.4 \mathrm{fg}$ [28]. Theoretically, MTB DNA prepared in $50 \mathrm{fg} / \mu \mathrm{L} \times 1 \mu \mathrm{L}$ (Fig. $4 \mathrm{~A}$ ), $5 \mathrm{fg} / \mu \mathrm{L} \times 1 \mu \mathrm{L}$ (Fig. 4B), and $0.5 \mathrm{fg} / \mu \mathrm{L} \times 10 \mu \mathrm{L}$ (Fig. 4C) aliquots approximate those from 10 bacilli $/ \mu \mathrm{L} \times 1 \mu \mathrm{L}, 1$ bacillus $/ \mu \mathrm{L} \times 1 \mu \mathrm{L}$, and 100 bacilli $/ \mathrm{mL} \times 10 \mu \mathrm{L}$, respectively. Although equivalent amounts of DNA aliquots are not exactly the same as those of intact bacilli, it is interesting enough to have an estimate of detectable mycobacterial concentration based upon above findings.
The probability of PCR amplification for detecting single DNA molecule could be calculated according to the equation of Poisson distribution.

$p(x ; \lambda)=\frac{\lambda^{x} e^{-\lambda}}{x !}, \quad x=0,1,2, \ldots$

$\lambda$ is the average number of template molecules before amplification, and $x$ is an occurrence in a certain volume. If the average number of template molecules before amplification were 1 , the probability of successfully taking DNA occurrences per microliter is $63.2 \%$. Assuming that each single-molecule PCR reaction had a successful amplification, the sampling probability of singlemolecule detection can be deduced by Poisson distribution [25]. Since the average number of template molecules before amplification is 1.14 ( 5 fg versus $4.4 \mathrm{fg}$ ), the probability of successfully taking DNA occurrences per microliter is 68.0\%. Our probabilities for DNA molecule detection in one bacillus, $25-68.8 \%$ and 18.8-56.2\%, are lower than Poisson distribution. The differences could be resulted from null sampling with single DNA molecule adsorbed on the surface of pipette tip. It may also due to inefficient amplification with only a few templates [25]. Thus, our nPCR results of probability indicate that all specimens with concentration of 10 bacilli/ $\mu \mathrm{L}$ are detectable. For specimens with concentration of 1 bacillus $/ \mu \mathrm{L}$, the rate of detection is $25-68.8 \%$. For specimens containing 100 bacilli $/ \mathrm{mL}$, the detection rate is $18.8-56.2 \%$ with $10 \mu \mathrm{L}$ examined. Such a detection limit is much more sensitive than that of acid-fast bacilli smear (5000-10,000 bacilli/mL), and may reach the upper limit of sensitivity of culture method (10-100 bacilli/mL) [25].

\subsection{Identification of the mycobacterium species from sputum}

In the present study, we chose nine AFB-positive sputum specimens labeled from No.1 to No.9 and analyzed them with conventional PCR and nPCR for comparison. Before amplification, all sputum specimens had been treated with QIAamp DNA Mini Kit. The presence of amplification products were then demonstrated by $3 \%$ agarose electrophoretic gels. In PRA using conventional PCR (Fig. 5A), obvious formation of primer-dimers was noted. While PRA adopting nPCR (Fig. 5B), hsp65 gene bands became brighter and primer-dimers formation disappeared. Among nine specimens, No.5 fails to generate $h s p 65$ gene band in PRA using conventional PCR, but it has remarkable hsp65 gene products when analyzed with nPCR. As shown by capillary electrophoregrams, conventional PCR products of specimen No.5 separated by CE reveals a tiny 442 bp hsp65 gene peak and some primer-dimers formation (Fig. 6A). The primer-dimers usually interfere with RFLP patterns by generating unrecognizable peaks after enzymatic digestion. The presence of inhibitors is indicated by the poor enhancement of hsp65 gene peak following $50 \mathrm{pg}$ spike of MTB DNA (Fig. 6B). When analyzed by nPCR, the formation of primer-dimers and the inhibition of amplification vanish as evidenced by a single 10 -fold taller hsp65 gene

Table 2

Comparison of results between AFB smear, culture, nPCR, and sequencing analysis for identification of mycobacteria in sputum

\begin{tabular}{|c|c|c|c|c|}
\hline Specimen No. & AFB smear & Culture & $\mathrm{nPCR}$ & Sequencing \\
\hline 1 & $1+$ & M. fortuitum & M. chelonae & M. chelonae \\
\hline 2 & $1+$ & No growth & M. tuberculosis & M. tuberculosis \\
\hline 3 & $1+$ & M. abscessus & M. chelonae & M. chelonae \\
\hline 4 & $1+$ & M. chelonae & M. chelonae & M. chelonae \\
\hline 5 & $2+$ & M. fortuitum & M. abscessus & M. abscessus \\
\hline 6 & $2+$ & M. tuberculosis & M. tuberculosis & M. tuberculosis \\
\hline 7 & $2+$ & M. tuberculosis & M. tuberculosis & M. tuberculosis \\
\hline 8 & $3+$ & M. abscessus & M. chelonae & M. chelonae \\
\hline 9 & $3+$ & M. tuberculosis & M. tuberculosis & M. tuberculosis \\
\hline
\end{tabular}



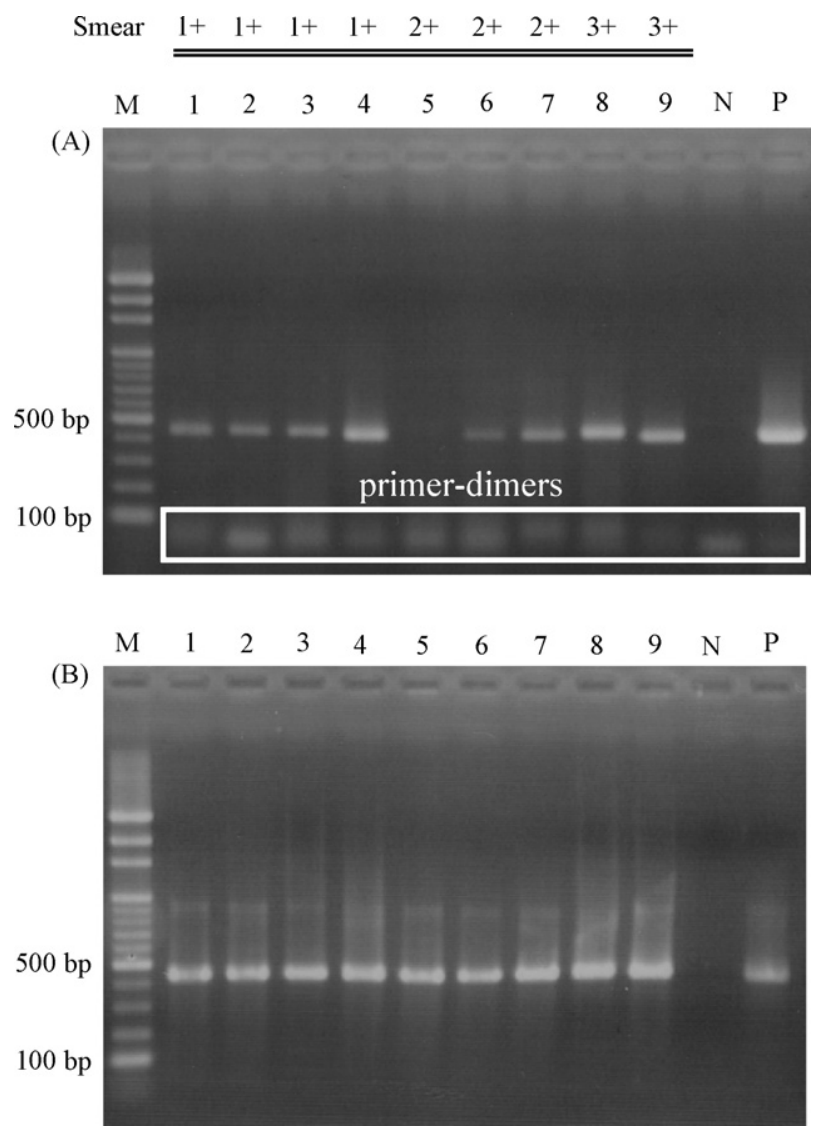

Fig. 5. Agarose electrophoretic gels demonstrating $h s p 65$ gene bands generated from conventional PCR (A) and nPCR (B) of mycobacteria in sputum. Lanes 1-9: nine specimens with smear positive $(1+$ to $3+$ ) for AFB, M: 100-bp DNA ladder, $\mathrm{N}$ : human genomic DNA as negative control, P: MTB DNA as positive control.

peak (Fig. 6C). A distinct full-range RFLP pattern is obtained from $\mathrm{nPCR}$ products after enzymatic digestion (Fig. 6D). According to the database of RFLP patterns established in previous study [25], specimen No.5 is consistent with M. abscessus. Specimens No.1, 3, 4, 8 are consistent with Mycobacterium chelonae (Fig. 6E) and specimens No.2, 6, 7, 9 are consistent with MTB (Fig. 6F).

The PRACE results of mycobacterial identification in sputum were compared with those of culture method and sequence analysis (Table 2). There are discrepancies of mycobacterium species identified between the culture method and PRACE. Of four specimens found to contain MOTT by culture, two differences were initially identified; specimen No.1 was identified as M. chelonae and specimen No.5 was identified as M. abscessus by PRACE, whereas they were later shown to be Mycobacterium fortuitum by culture. Similarly, specimen No.3 and No.8 were identified as M. chelonae by PRACE but were identified as M. abscessus by culture. These disagreements are not surprising because identification of rapidly growing mycobacteria to the species level relies on phenotypic tests in most laboratories [29]. The commonest error Ringuet et al. found in databases was the misidentification between $M$. chelonae and $M$. abscessus [30]. They are the most closely related species with hsp65 sequences that differ by nearly 30 nucleotides, whereas their $16 \mathrm{~S}$ rRNA genes differ by only four nucleotides. We selected the hsp65 gene for our CE-based PRA, because its sequence has more variability than the 16S rRNA gene, and could be exploited to identify both slowly and rapidly growing mycobacteria. According to the sequence analysis of mycobacterial hsp65 gene, PRACE was found to be more accurate than culture method in terms of species dif-
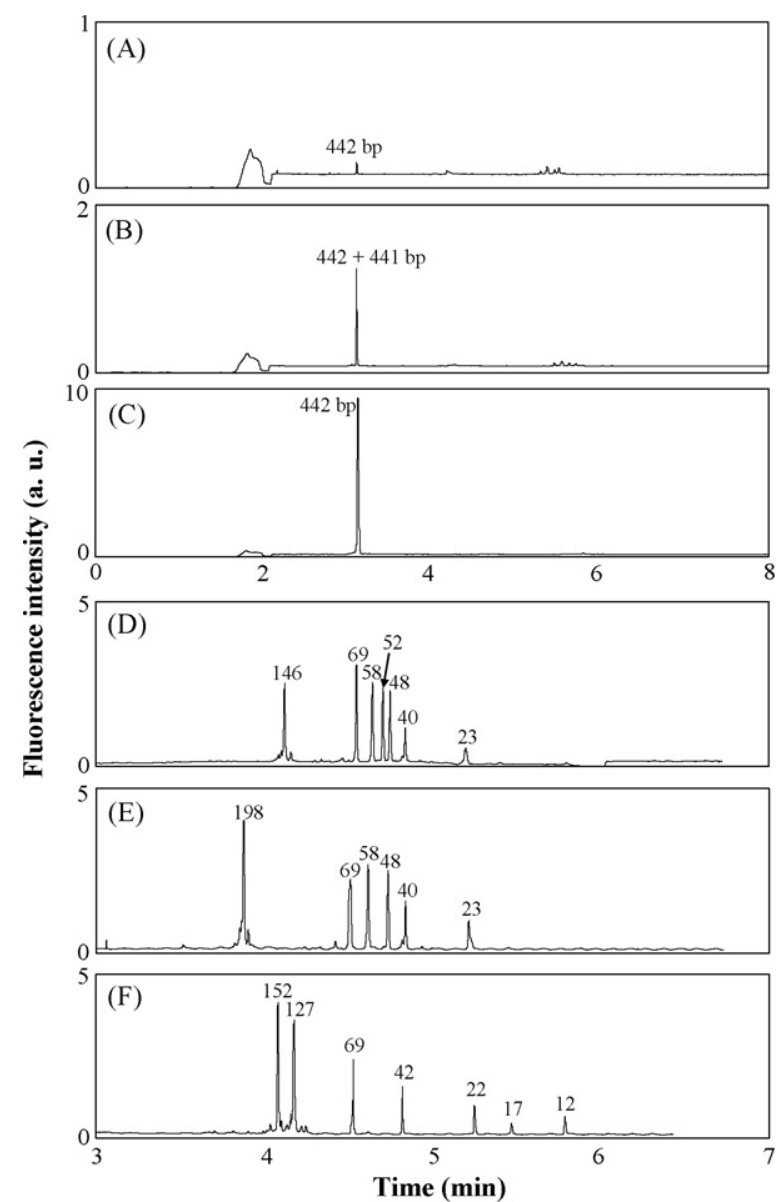

Fig. 6. CE of specimen No.5 (A-D): conventional PCR products (A), poor enhancement of $h s p 65$ gene peak following $50 \mathrm{pg}$ spike of MTB DNA (B), the nPCR products (C), RFLP pattern of nPCR products (D). RFLP patterns of nPCR products from specimens No.1, 3, 4, 8 (E) and No. 2, 6, 7, 9 (F).

ferentiation for MOTT. One culture-negative specimen (specimen No.2) gives a positive result by PRACE. This specimen is AFB smear $(1+)$, but reveals no growth despite prolonged incubation in both liquid and solid culture systems. It probably represents the presence of non-viable mycobacteria, which is identified as MTB by PRACE and sequence analysis.

\section{Conclusions}

Practically speaking, there are at least two major problems in the rapid identification of mycobacterial species. One is the lack of an ultra-sensitive screening method for false smear-negative cases which are responsible for about $17 \%$ of tuberculosis transmission [10]. The other is the absence of a highly specific technique for diagnosing diseases caused by an increasing number of medically important MOTT species [2]. As our results shown, the advantages of nPCR and high-resolution CE enable PRACE to identify MTB and MOTT with minimal interferences of primer-dimers and inhibitors. For a limited number of specimens, the PRACE is not only able to differentiate the species, but detect the presence of individual DNA as well. Such an improvement is encouraging for our team to further evaluate a large quantity of specimens directly from clinical isolates, especially false AFB smear-negative cases and various species of MOTT. In conclusion, the PRACE using nPCR and high-resolution CE provides a potential alternative for rapidly identifying small amount of various mycobacterial species directly from sputum. 


\section{Acknowledgements}

This work was supported by the grants from the National Science Council of Taiwan (NSC 96-2320-B-195-001 and NSC 95-2113-M002-026-MY3) and Mackay Memorial Hospital (MMH Grant 9721 and 9454). We would also like to thank the Cleveland Clinic for providing our study the DNA of mycobacteria as gift.

\section{References}

[1] F.A. Drobniewski, M. Caws, A. Gibson, D. Young, Lancet Infect. Dis. 3 (2003) 141.

2] J.O. Falkinham, Clin. Microbiol. Rev. 9 (1996) 177.

[3] T.J. Brown, E.G. Power, G.L. French, J. Clin. Pathol. 52 (1999) 193.

[4] U. Reischl, N. Lehn, H. Wolf, L. Naumann, J. Clin. Microbiol. 36 (1998) 2853.

[5] C. Piersimoni, A. Callegaro, C. Scarparo, V. Penati, D. Nista, S. Bornigia, C. Lacchini, M. Scagnelli, G. Santini, G. De Sio, J. Clin. Microbiol. 36 (1998) 3601.

[6] T.J. Hellyer, T.W. Fletcher, J.H. Bates, W.W. Stead, G.L. Templeton, M.D. Cave, K.D. Eisenach, J. Infect. Dis. 173 (1996) 934

[7] F. Brunello, M. Ligozzi, E. Cristelli, S. Bonora, E. Tortoli, R. Fontana, J. Clin. Microbiol. 39 (2001) 2799.

[8] A. Roth, U. Reischl, A. Streubel, L. Naumann, R.M. Kroppenstedt, M. Habicht, M. Fischer, H. Mauch, J. Clin. Microbiol. 38 (2000) 1094

[9] E. Tortoli, Clin. Microbiol. Rev. 16 (2003) 319.

[10] M.A. Behr, S.A. Warren, H. Salamon, P.C. Hopewell, A.P. de Leon, C.L. Daley, P.M. Small, Lancet 353 (1999) 444.

[11] T.R. Frieden, T.R. Sterling, S.S. Munsiff, C.J. Watt, C. Dye, Lancet 362 (2003) 887.

[12] C.V.S. Babu, E.J. Song, S.M. Babar, M.H. Wi, Y.S. Yoo, Electrophoresis 27 (2006) 97.
[13] E.J. Song, S.M. Babar, E. Oh, M.N. Hasan, H.M. Hong, Y.S. Yoo, Electrophoresis 29 (2007) 129.

[14] P.-L. Chang, W.-S. Hsieh, C.-L. Chiang, M.J. Tuohy, G.S. Hall, G.W. Procop, H.-T Chang, H.-T. Ho, Diagn. Microbiol. Infect. Dis. 58 (2007) 315.

[15] H.-T. Ho, P.-L. Chang, C.-C. Hung, H.-T. Chang, J. Clin. Microbiol. 42 (2004) 3525

[16] H.-S. Chen, H.-T. Chang, Anal. Chem. 71 (1999) 2033.

[17] W.-L. Tseng, H.-T. Chang, Electrophoresis 22 (2001) 763.

[18] P.T. Kent, G.P. Kubica, Public Health Mycobacteriology: A Guide For The Level IIl Laboratory, US Department of Health and Human Services, Atlanta, 1985.

[19] A. Telenti, F. Marchesi, M. Balz, F. Bally, E.C. Bottger, T. Bodmer, J. Clin. Microbiol. 31 (1993) 175.

[20] C.R. Bascunana, K. Belak, J. Clin. Microbiol. 34 (1996) 2351.

[21] M.J. McPherson, S.G. Møller, PCR (The Basics), Springer-Verlag, New York, 2000

[22] I.G. Wilson, Appl. Environ. Microbiol. 63 (1997) 3741.

[23] B. Böddinghaus, T.A. Wichelhaus, V. Brade, T. Bittner, J. Clin. Microbiol.39(2001) 3750.

[24] J.-H. Lu, H.-K. Li, H.-J. An, G.-H. Wang, Y. Wang, M.-Q. Li, Y. Zhang, J. Hu, J. Am Chem. Soc. 126 (2004) 11136.

[25] G. Ruano, K.K. Kidd, J.C. Stephens, Proc. Natl. Acad. Sci. U.S.A. 87 (1990) 6296

[26] E.T. Lagally, I. Medintz, R.A. Mathies, Anal. Chem. 73 (2001) 565.

[27] S.T. Cole, R. Brosch, J. Parkhill, T. Garnier, C. Churcher, D. Harris, S.V. Gordon, K Eiglmeier, S. Gas, C.E. Barry III, F. Tekaia, K. Badcock, D. Basham, D. Brown, T. Chillingworth, R. Connor, R. Davies, K. Devlin, T. Feltwell, S. Gentles, N. Hamlin, S. Holroyd, T. Hornsby, K. Jagels, A. Krogh, J. McLean, S. Moule, L. Murphy, K. Oliver, J. Osborne, M.A. Quail, M.A. Rajandream, J. Rogers, S. Rutter, K. Seeger, J. Skelton, R. Squares, S. Squares, J.E. Sulston, K. Taylor, S. Whitehead, B.G. Barrell Nature 393 (1998) 537.

[28] D. Hillemann, R. Warren, T. Kubica, S. Rusch-Gerdes, S. Niemann, J. Clin. Microbiol. 44 (2006) 302.

[29] S. Pai, N. Esen, X. Pan, J.M. Musser, Arch. Pathol. Lab. Med. 121 (1997) 859

[30] H. Ringuet, C. Akoua-Koffi, S. Honore, A. Varnerot, V. Vincent, P. Berche, J.L. Gaillard, C. Pierre-Audigier, J. Clin. Microbiol. 37 (1999) 852 